\title{
Analysis of Heat Treatment Parameters on the Properties of Selected Tool Steels M390 and M398 Produced with Powder Metallurgy
}

\author{
Róbert Cíger, Igor Barényi (0000-0002-9296-600X), Michal Krbat’a (0000-0002-0520-8180) \\ Faculty of Special Technology, Alexander Dubcek University of Trencin. Ku kyselke 469, 91106 Trencin. Slovakia. \\ E-mail: robert.ciger@tnuni.sk
}

This paper deals with the comparison of two tool steels M390 and M398 produced by powder metallurgy of the MICROCLEAN type. The primary use of steel is in the plastics industry to produce screws for injection molding machines. The main purpose of the paper is to analyze the hardness after different stages of heat treatment. The first part of the article evaluates the hardness of steels after hardening, which was performed using a hardening dilatometer DIL805A. A total of 8 different controlled cooling measurements were performed, for both types of powdered tool steels, from a maximum rate of $100{ }^{\circ} \mathrm{C} / \mathrm{s}$ to a minimum of $0.01^{\circ} \mathrm{C} / \mathrm{s}$. Based on the results of the first set of samples from the hardening dilatometer, the optimal cooling time is evaluated to achieve the highest hardness of both materials. This rate was used to heat treat a second set of samples that had undergone a quenching process from which a selected group was quenched to $-78^{\circ} \mathrm{C}$. Freezing was performed to reduce the amount of residual austenite. Before measuring the hardness, the samples were tempered at temperatures of $200,400,600^{\circ} \mathrm{C}$ for $2 \times 2 h$. The measured hardness values were then compared with data from the manufacturer BÖHLER.

Keywords: Powder metallurgy, Tool steel, M398, M390, Martensite

\section{Introduction}

Most high-quality tool steels are produced by the traditional process of melting the base metal, additive elements, and subsequent casting into ingots, which can result in segregation of the additive elements due to slow cooling rate. This can lead to a reduction in the quality of the resulting steel. Bohler therefore uses a powder metallurgy process to produce M390 and M398 powder steels, which makes it possible to create steel with a very fine distribution of carbides and alloying elements.[1] The production process begins by melting the base material in an induction furnace. A sample is taken from the material for chemical composition analysis. Subsequently, the material is melted again in an arc furnace. To ensure high homogeneity, the metal is mixed by electromagnetic stirring. Unlike ingot casting, molten metal is sprayed into a chamber with a protective nitrogen atmosphere which allows the formation of a very fine metal powder.[2] Rapid cooling will allow the formation of a powder having a high homogeneity with a fine dispersion of several types of carbides. Subsequently, the powder is placed in thin-walled cylindrical containers and, by welding, the containers are closed and placed in an isostatic press. In the press itself, the individual powder particles are sintered under a pressure of $1000 \mathrm{bar}$ and a temperature of $1150^{\circ} \mathrm{C}$. The combination of high pressure and temperature will allow the particles to bond completely without additional porosity. Investigating the porosity of steels and the effect on their properties is addressed by Amini et al. and Warke et al. in [3,4]. After cooling, a reduction in the height and diameter of the containers is roughly $10 \%$. The result of powder metallurgy is a special tool steel. The resulting microstructure consist of very fine carbides evenly distributed throughout the volume of the material. The whole production process of the investigated powdered tool steels M390 and M398 is shown in Fig. 1 , after which we obtain a homogeneous tool steel without segregation with practically isotropic properties.

Powder metallurgy is currently considered as a progressive method of steel production that can produce tool steel with higher amount of alloying elements than conventional metallurgy.[5] From an energy point of view, this process is several times more demanding than conventional foundry technologies, in which energy consumption is in principle limited to melting the base materials and cast into ingots. However, the resulting steel formed by powder metallurgy may have properties far superior to conventionally produced steels in terms of hardness, strength, and corrosion resistance.

The investigated steels that we will deal with in this article are Böhler M390 and M398. Both steels are chromium martensitic steels produced by the process of powder metallurgy. A potential use of M398 steel is to replace the older M390 steel in the plastics industry, specifically as a material to produce screw conveyors. The screws are exposed to elevated temperatures, me- 
chanical stress as well as aggressive chemical environments during operation. For this reason, increased requirements are placed on the material of the screws. The implementation of M398 steel in the production of screws is expected to have an effect in the form of increased operational capability as well as production in terms of the use of plastics with a higher glass content.

The investigated steel has a high chromium content, which contributes not only to increased hardness and abrasion ability but also to corrosion resistance.

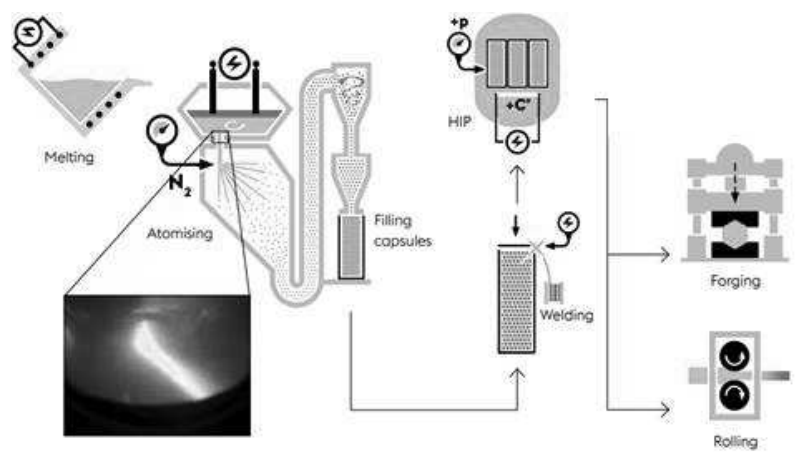

Fig. 1 The process of production of steel produced by powder metallurgy $[6]$

Dilatometric analysis is an experimental method used to study the phase transformations of metals and their alloys. The method uses volume changes associated with phase changes and is based on recording the change in the length of the experimental sample due to the temperature during its heating and cooling [7]. We will use the DIL805A/D hardening dilatometer for the physical simulation of heat treatment. Dilatometric device is a laboratory device that is used either to measure and record expansion curves or measure hot deformation resistances. It is intended for physical modeling of heat treatment processes $(805 \mathrm{~A})$ or hot metal forming processes (805D) [8,9]. An experimental sample of the prescribed shape and dimensions is placed in the working chamber between $\mathrm{Al}_{2} \mathrm{O}_{3}$ rods. The rods are connected to a precision extensometer, which thus records changes in length during the execution of the set temperature cycle.

\section{Materials and methods}

M390 and M398 steels are chromium martensitic tool steels. The production process is powder metallurgy of the MICROCLEAN type. The main essence of powder steel production is the sintering of metal powders in order to form a compact non-porous steel. The reason for using the powder metallurgy process is the high proportion of alloying elements that make it impossible to produce steel by conventional casting. The main alloying element is chromium in amounts up to $20 \%$, thanks to chromium content the steel has a high strength, resistance to abrasive wear and resistance to corrosion. The total chemical composition can be seen in Table 1, where the data provided by the manufacturer are compared with the result of the spectral analysis performed on the SPECTROLAB Jr. instrument. These properties predetermine M390 steel to produce screws for injection molding machines, which are stressed thermally and mechanically in a chemically aggressive environment during their operation. M398 steel is a potential replacement for M390 steel.

Tab. 1 Chemical composition of the M390 and M398 steel (wt. \%)

\begin{tabular}{|c|c|c|c|c|c|c|c|}
\hline & C & $\mathbf{S i}$ & $\mathbf{M n}$ & $\mathbf{C r}$ & $\mathbf{M o}$ & $\mathbf{V}$ & W \\
\hline BOHLER M390 & 1.90 & 0.70 & 0.30 & 20.00 & 1.00 & 4.00 & 0.60 \\
\hline BOHLER M398 & 2.70 & 0.50 & 0.50 & 20.00 & 1.00 & 7.20 & 0.70 \\
\hline SPECTROLAB Jr. M390 & 1.98 & 1.19 & 0.38 & 20.37 & 0.85 & 4.02 & 0.33 \\
\hline SPECTROLAB Jr. M398 & 2.65 & 0.55 & 0.51 & 20.09 & 1.00 & 7.1 & 0.43 \\
\hline
\end{tabular}

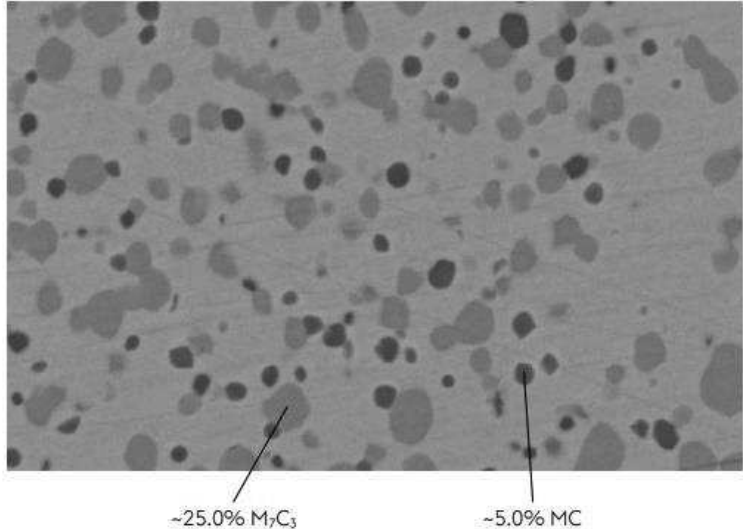

a)

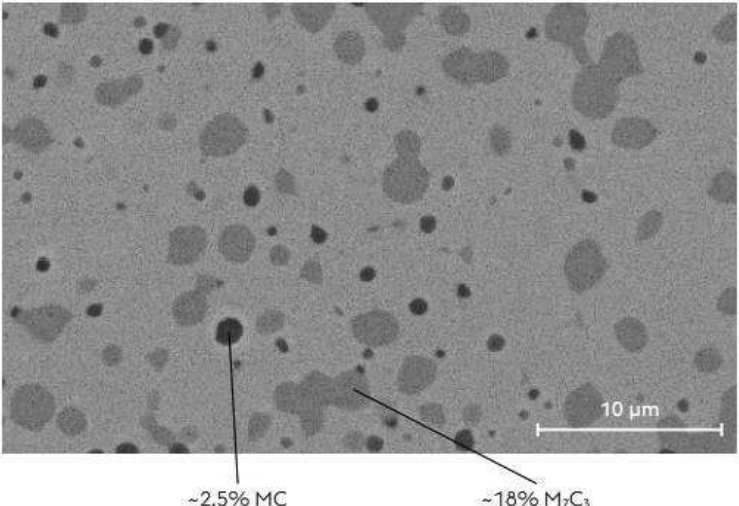

b)

Fig. 2 Microstructure of M390 and M398 [10] 
The high chromium content results in the formation of carbides, primarily chromium based $\mathrm{M}_{7} \mathrm{C}_{3}$ type carbides and $\mathrm{MC}$ carbides. BÖHLER reports a percentage of $\sim 25 \% \mathrm{M}_{7} \mathrm{C}_{3}$ and $\sim 2.5 \% \mathrm{MC}$.

The diagram of the phase fractions for steel M390 can be seen in Fig.3 a) and for steel M398 in Fig.3 b). The diagrams were created using THERMOCALC software. For carbon content up to $3 \%$. Created thereby are diagrams useful tool in analyzing the dilatometric curve for the assessment of the formation of the phase.
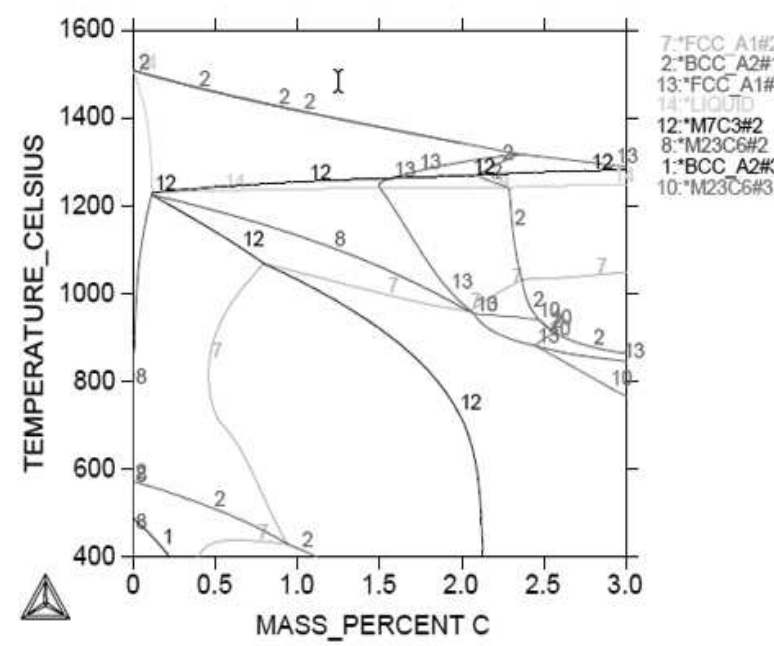
3." $\mathrm{FCC}$ A1\# 19. 8: $\mathrm{M} 23 \mathrm{C} 6 \mathrm{H} 2$ $1: B C C$ A2 $\# 3$ 10:" M23C $6+3$

a)

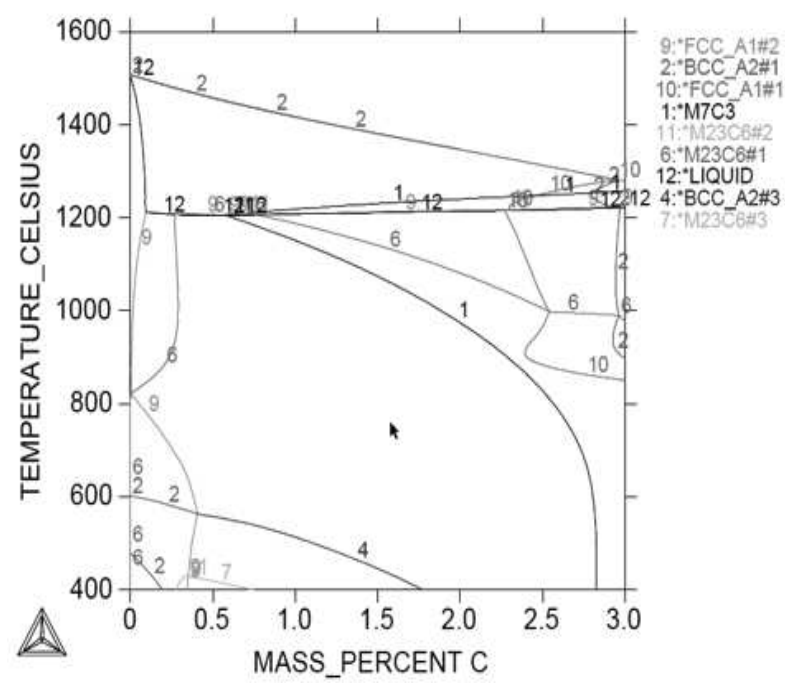

b)

Fig. 3 Phase fraction of M390 and M398

In the first part of the experiment, the first set of samples was prepared according to Fig.4. With the help of a dilatometric device, a simulation of heat treatment was performed according to defined parameters, the result of dilatometric analysis are dilatation curves and heat-treated samples. Those heat-treated samples of steel samples m398 and M390 were further evaluated in terms of the resulting hardness. The total number of samples is 16 , for each selected steel 8 .

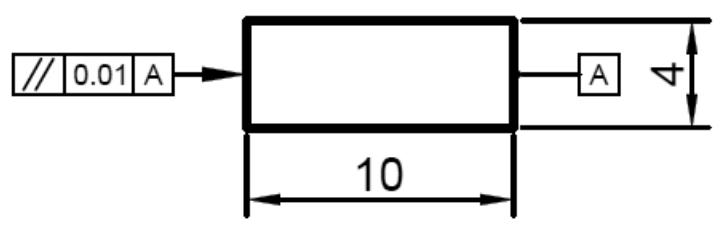

Fig. 4 DIL 805 A sample dimensions

The DIL 805A dilatometer was used to simulate the heat treatment, which allows to accurately simulate the heat treatment according to the specified parameters. The experimental sample is placed in the working chamber Fig. 5 between the $\mathrm{Al} 2 \mathrm{O} 3$ rods. The rods are connected to a precision extensometer, which thus records changes in length during the execution of the set temperature cycle. [9] The heating of the sample is provided by induction heating, the advantage of which is the possibility of precise power control to achieve the optimal heating rate. $[11,12,13]$

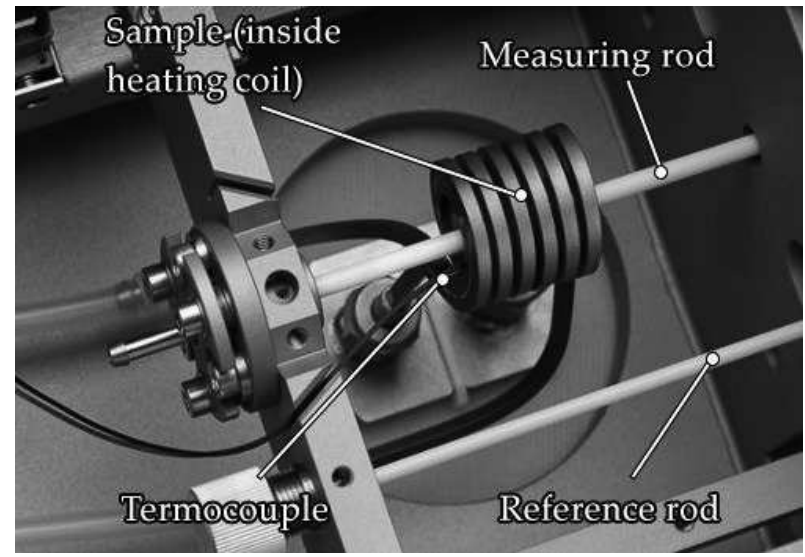

Fig. 5 chamber of DIL 805 A

The heat treatment of the first set of samples will consist of heating the sample from room temperature up to $1150^{\circ} \mathrm{C}$. Subsequently, a temperature holding time occur, which allows the temperature gradient to be reduced over the entire cross-section of the sample. After holding time stage, the cooling of the sample occurs in the selected mode. We heated all examined samples with the same parameters. The cooling was rapid from $100^{\circ} \mathrm{C} / \mathrm{s}$ to slow $0.01 \mathrm{C} / \mathrm{s}$. The exact parameters of heat treatment are given in Table 2 . The hardening process is identical for both investigated steels and its graphical course is shown in Fig. 6.

The hardness was measured on an INSTRON WOLPERT TESTOR. It is a hardness tester using Vickers HV10 method. The tip of the measuring instrument was pressed into the measured sample with a force of $98.07 \mathrm{~N}$ for $10 \mathrm{~s}$. The aim of the measurement is to find out which of the selected cooling modes during heat treatment allows to achieve the highest hardness of the sample. 
Tab. 2 Input cooling parameters for selected temperature modes of dilatometric analysis of M390 and M398 steel

\begin{tabular}{|c|c|c|c|c|c|c|}
\hline \multirow{2}{*}{} & \multicolumn{3}{|c|}{$\begin{array}{c}\text { Cooling time } \\
\mathrm{T}_{\max } \text { to } \mathrm{T}_{\min }\end{array}$} & Cooling rate & $\mathrm{T}_{\max }$ & $\mathrm{T}_{\min }$ \\
\cline { 2 - 6 } & $t[\mathrm{~s}]$ & $t[\mathrm{~min}]$ & $t[\mathrm{hr}]$. & $v\left[{ }^{\circ} \mathrm{C} / \mathrm{s}\right]$ & {$\left[{ }^{\circ} \mathrm{C}\right]$} & {$\left[{ }^{\circ} \mathrm{C}\right]$} \\
\hline 1 & 11 & 0.18 & 0 & 100 & 1150 & 50 \\
\hline 2 & 110 & 1.83 & 0 & 10 & 1150 & 50 \\
\hline 3 & 220 & 3.67 & 0 & 5 & 1150 & 50 \\
\hline 4 & 1100 & 18.33 & 0.31 & 1 & 1150 & 50 \\
\hline 5 & 2200 & 36.67 & 0.61 & 0.5 & 1150 & 50 \\
\hline 6 & 11000 & 183.33 & 3.06 & 0.1 & 1150 & 50 \\
\hline 7 & 22000 & 366.67 & 6.11 & 0.05 & 1150 & 50 \\
\hline 8 & 110000 & 1833.33 & 30.56 & 0.01 & 1150 & 50 \\
\hline
\end{tabular}

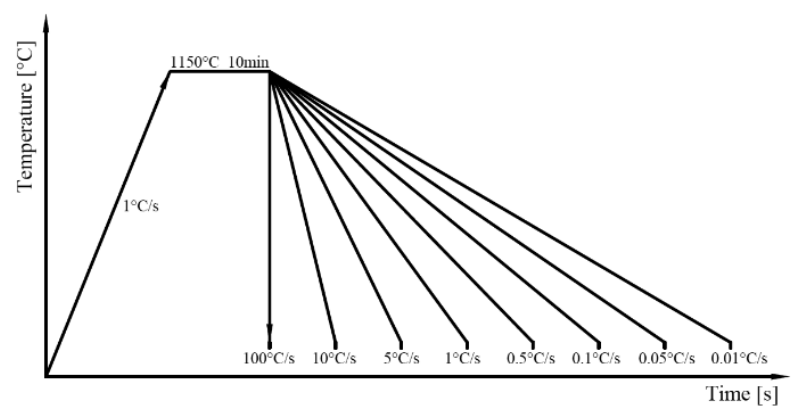

Fig. 6 graphical representation of the cooling process of steel m390 and M398

In the second part of the experiment, we prepared 6 samples for each of the examined tool steels. The samples were heated to $1150^{\circ} \mathrm{C}$ and then quenched into oil. Oil as a cooling medium was chosen based on the results of previous experiments, which confirmed the increase in hardness with increasing cooling rate. 6 samples were prepared for each steel, of which 3 samples were quenched and subsequently tempered to a temperature of $200,400,600^{\circ} \mathrm{C}$ fig 7 a). The remaining 3 samples were quenched followed by subzero cooling at $-78^{\circ} \mathrm{C}$ after which tempering occurred similarly to the previous samples. Graphical course of hardening with freezing is shown in fig. $7 \mathrm{~b}$ ).

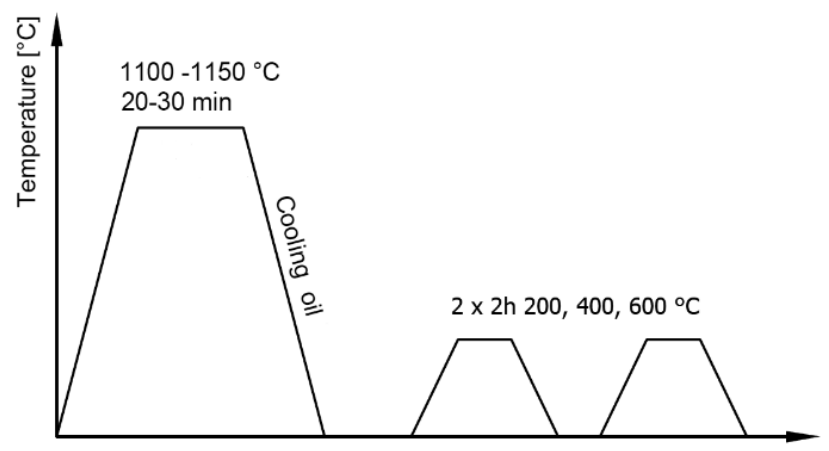

a)

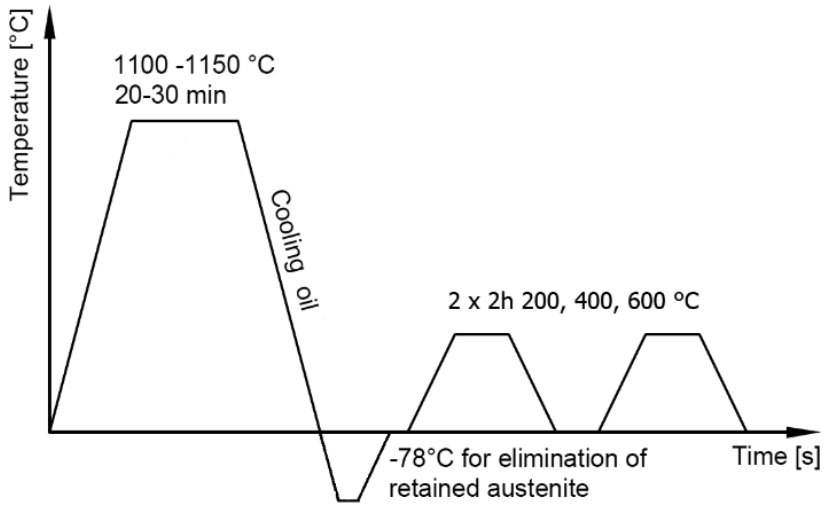

b)

Fig. 7 graphical representation of the tempering process of steel m390 and M398

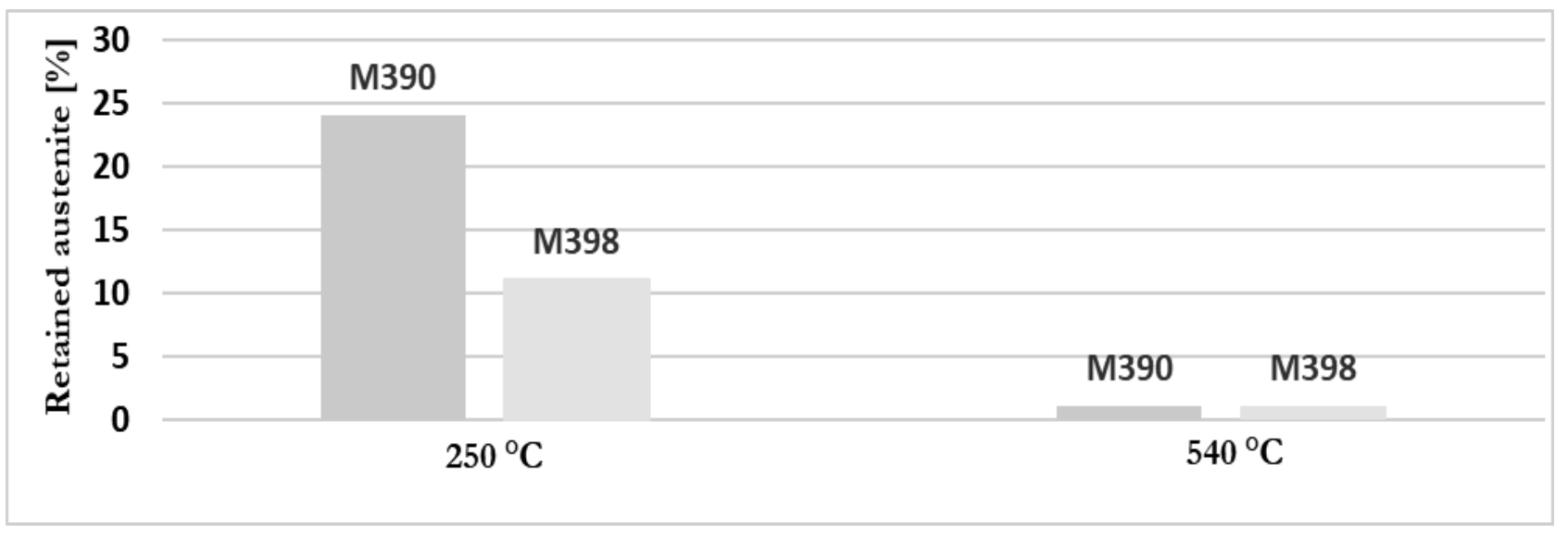

Fig. 8 Theoretical amount of retained austenite after tempering of M390 and M398 steel 
The purpose of subzero cooling after quenching is to reduce the amount of residual austenite. Another possibility to reduce the amount of residual austenite is by tempering. [14] The theoretical decrease in the amount of residual austenite after tempering can be seen in Fig.8.

\section{Results a discussion}

The hardness results of the first series of samples for steel M390 and M398 are given in Table XZ, which is the average value of hardness from a total of three measurements for each sample. As we can see, M398 steel achieves greater hardness at cooling rates at which a primarily martensitic structure is formed. The presence of a martensitic structure can be demonstrated based on the dilatation curve Fig. 9 a) where the step change at $246{ }^{\circ} \mathrm{C}$ indicates the beginning of martensite formation. For steel M390, the formation of martensite begins at a temperature $\mathrm{Ms}=413{ }^{\circ} \mathrm{C}$ according to the curve Fig.10 a). With decreasing cooling rate, there is a slight change in the trend where the hardness of steel m398 decreases to $669.3 \mathrm{HV}$ while the hardness of steel M390 is $724.3 \mathrm{HV}$. The hardness of steels continues to decrease with decreasing cooling rate. At slow cooling rates, M398 steel again achieves a higher hardness than M390 steel.

Tab. 3 Hardness after quenching of the first set of samples

\begin{tabular}{|c|c|c|c|c|c|c|c|c|c|}
\hline & \multicolumn{8}{|c|}{ Cooling speed $\left[{ }^{\circ} \mathrm{C} / \mathrm{s}\right]$} \\
\hline & & 100 & 10 & 5 & 1 & 0.5 & 0.1 & 0.05 & 0.01 \\
\hline \multirow{2}{*}{$\begin{array}{c}\text { Hardness } \\
{[\mathrm{HV}]}\end{array}$} & M390 & 792 & 780.3 & 774.7 & 724.3 & 679 & 267 & 261.3 & 239 \\
\hline & M398 & 846 & 823.6 & 786.6 & 669.3 & 584 & 333.3 & 340.6 & 284.5 \\
\hline
\end{tabular}

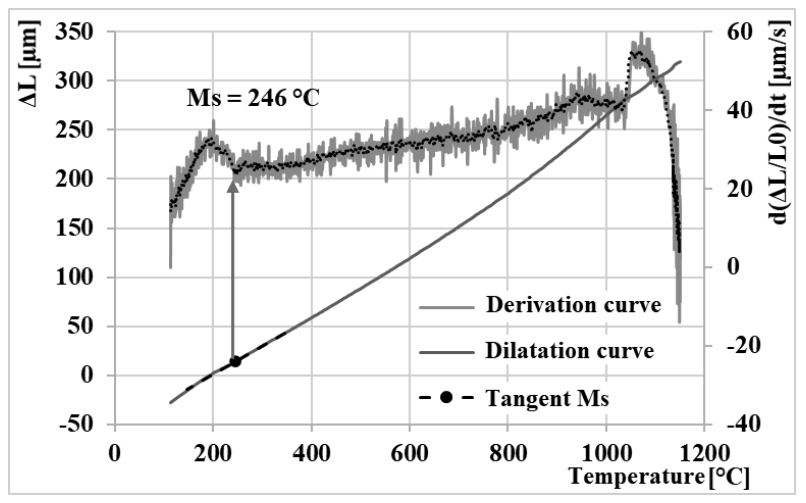

a)

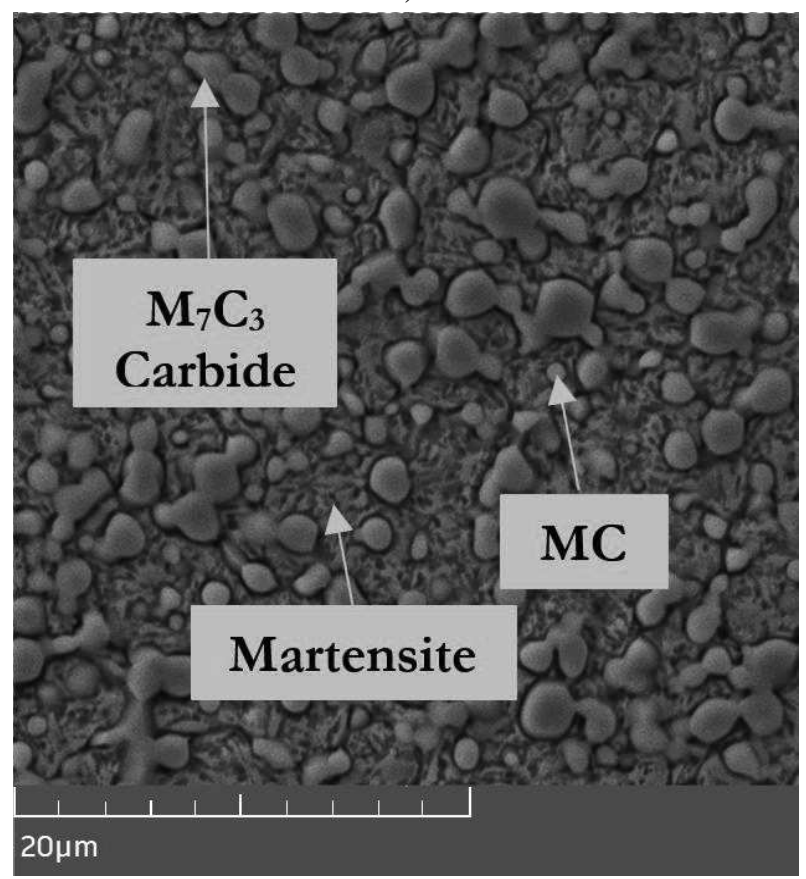

b)

Fig. 9 Dilatation curve and microstructure of M398 steel

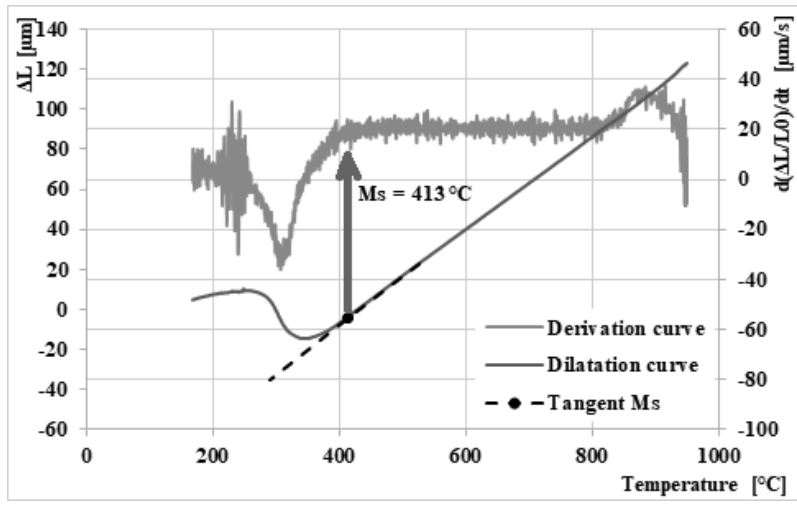

a)

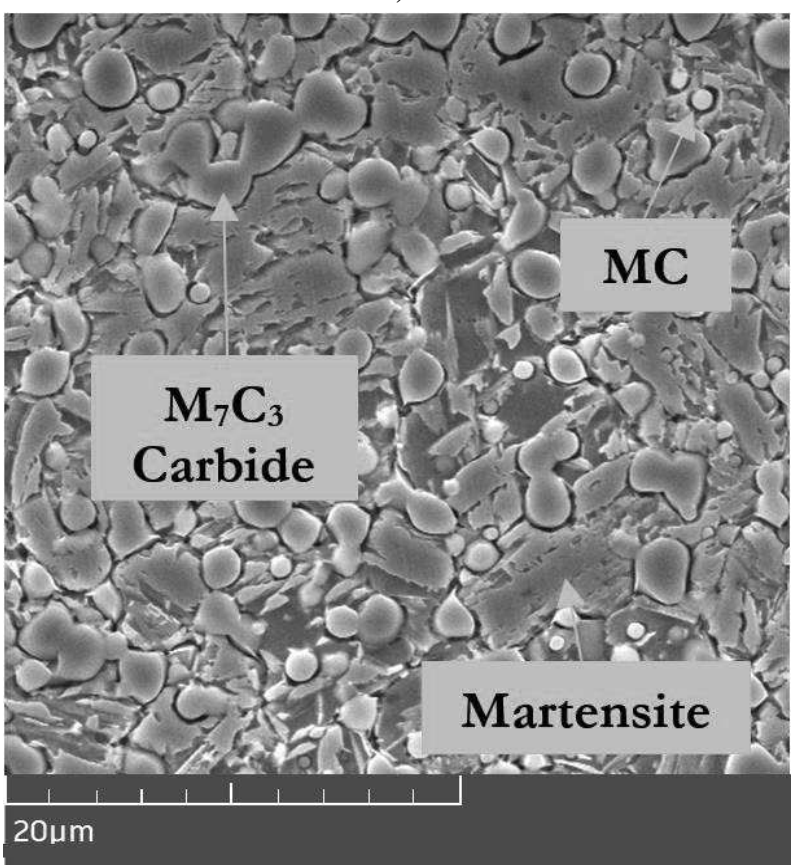

b)

Fig. 10 Dilatation curve and microstructure of M390 steel 
We can say that the highest hardness for both types of steel were achieved at a maximum cooling rate of $100^{\circ} \mathrm{C} / \mathrm{s}$. Therefore, the pair of samples were ground and etched to observe the microstructure. In addition to martensite, the microstructure also contains residual austenite that the exact amount has not been evaluated. A detailed examination of the microstructure of both steels confirmed the presence of carbides $\mathrm{M}_{7} \mathrm{C}_{3}$ and $\mathrm{MC}$ based on $\mathrm{Cr}$ and $\mathrm{V}$.

We used two methods to reduce the amount of residual austenite, the first was to use subzero cooling Tab. 4 Hardness after tempering second set of samples after quenching to $-78^{\circ} \mathrm{C}$ and then the samples were tempered [13]. In the second case, the amount of residual austenite decreases during the tempering itself. Measurements have shown that M398 steel achieves higher hardness than M398 even without the use of hardening to negative temperatures. On average, the hardness decreased by $2.08 \%$ when subzero cooling was performed. The hardness of M390 steel increased by $7.76 \%$. This results in the fact that M398 steel is a more suitable choice for applications where it is not possible to apply freezing hardening.

\begin{tabular}{|c|c|c|c|c|c|c|}
\hline & \multicolumn{3}{|c|}{$\mathbf{M 3 9 0}$} & \multicolumn{3}{c|}{$\mathbf{M 3 9 8}$} \\
\cline { 2 - 7 } & $\mathbf{2 0 0}{ }^{\circ} \mathbf{C}$ & $\mathbf{4 0 0}{ }^{\circ} \mathbf{C}$ & $\mathbf{6 0 0}^{\circ} \mathbf{C}$ & $\mathbf{2 0 0}{ }^{\circ} \mathbf{C}$ & $\mathbf{4 0 0}{ }^{\circ} \mathbf{C}$ & $\mathbf{6 0 0}^{\circ} \mathbf{C}$ \\
\hline $\begin{array}{c}\text { Quenching with } \\
\text { subzero cooling }\end{array}$ & 735 & 717.5 & 455 & 806.5 & 815 & 506 \\
\hline
\end{tabular}

Like M398 steel, M390 steel retains high tempering strength at temperatures up to $500^{\circ} \mathrm{C}$. subsequently, at temperatures of $600^{\circ} \mathrm{C}$, a significant decrease in hardness occurs. The area of consumption of the final component must be considered to select the correct tempering temperature, as M390 and 398 powder steels can be heat treated for increased corrosion resistance or abrasion resistance. According to BÖHLER claim the highest resistance to corrosion is achieved at tempering temperatures in the range of $200-300^{\circ} \mathrm{C}$ and the highest resistance to abrasive wear in the range of tempering temperatures $510-560^{\circ} \mathrm{C}$.

\section{Conclusion}

This work deals with the simulation of heat treatment of tool steels produced by powder metallurgy. The theoretical part of the work describes the mechanical-chemical properties of steels together with phase diagrams created using TERMOCALC software. Subsequently, the first series of heat treatment simulations was performed using a dilatometric device, which resulted in not only heat-treated samples but also dilatation curves that demonstrated the formation of a martensitic phase at high cooling rates. Conclusions made based on dilatometric curves are also supported by metallographic analysis. The second series of samples was quenched in oil, optionally with additional freezing at $-78^{\circ} \mathrm{C}$. The samples were further tempered according to the given temperature regimes. The following conclusions can be drawn from this work:

- In steel M390 and M398 there is a demonstrable transformation of austenite to martensite at speeds of $100^{\circ} \mathrm{C} / \mathrm{s}$. The martensitic matrix contains two types of carbides of type M7C3 and MC, which are based on $\mathrm{Cr}$ and $\mathrm{V}$.
- Relevantly high strength is achieved at a cooling rate from $100^{\circ} \mathrm{C} / \mathrm{s}$ to $5^{\circ} \mathrm{C} / \mathrm{s}$, at this speed M390 steel reaches a hardness of $774.7 \mathrm{HV}$ and M398 steel a hardness of $786.6 \mathrm{HV}$, which is caused by the so-called Homogeneous martensitic structure.

- As the cooling rate decreases, the hardness of both steels also decreases significantly, due to the conversion of austenite to bainite and perlite, which causes a softer heterogeneous structure.

- The inclusion of hardening with subzero cooling is of significant technological importance only for M390 steel, as it is possible to achieve an increase in hardness of $7.76 \%$ after tempering.

- M398 steel is a suitable choice for applications where subzero cooling after quenching is not technologically possible.

\section{Acknowledgement}

This publication was created in the frame of the project: Advancement and support of R\&D for "Centre for diagnostics and quality testing of materials"in the domains of the RIS3 SK specialization, ITMS2014+:313011W442, based on the Operational Programme Integrated Infrastructure and funded from the European Regional Development Fund.

\section{References}

[1] H. KIM, J. Y. KANG, D. SON, T. H. LEE A K. M. CHO (2015). „Evolution of carbides in 
coldwork tool steels" Materials Characterization, 1. vyd.107, pp. 376-385, 2015.

[2] B. ZHENG, Y. LIN, Y. ZHOU A E. LAVERNIA (2009). „Gas Atomization of Amorphous Aluminum Powder: Part II. Experimental Investigation, " Metallurgical and Materials Transactions B, 1. vyd.40, pp. 995-1004, 2009.

[3] LAWLEY, A., MURPHY, TF. (2003) Metallography of powder metallurgy materials, pp.315-327. ELSEVIER SCIENCE INCSTE 800, 230 PARK AVE, NEW YORK, ISSN1044-5803.

[4] WARKE, VIRENDRA S., SISSON, RICHARD D., MAKHLOUF, MAKHLOUF M. (2011). The effect of porosity on the austenite to ferrite transformation in powder metallurgy steels, pp. 3533 - 3538. ELSEVIER SCIENCE SAPO BOX 564, 1001 LAUSANNE, SWITZERLAND ISSN09215093

[5] J. JIN, R. GAO, H. PENG, H. GUO, S. GON A B. CHEN (2020). „Rapid Solidification Microstructure and Carbide Precipitation Behavior in Electron Beam Melted HighSpeed Steel,“ Metall Mater Trans A, 1. vyd.51, pp. 2411-2429, 2020.

[6] BÖHLER metallurgy preces. Voestalpine BÖHLER Edelstahl GmbH \& Co KG [online]. 2021 [cit. 2021-06-15]. url: https://www.bohler-edelstahl.com/de/produktion/

[7] ZHONG ZHAN, Y., DU, Y., HONG ZHUANG, Y. (2007). Chapter four - determination of phase dia-grams using equilibrated alloys, In: Methods for Phase Diagram Determination, Elsevier Science Ltd, pp. 108-150, ISBN 9780080446295.

[8] BARÉNYI, I. (2018). Dilatometrická analýza ocele OCHN3MFA. pp.7. Trenčín.
[9] Dilatometry, TA Instruments. (2013), Hüllhorst, Germany.

[10] BÖHLER metallurgy preces. Voestalpine BÖHLER Edelstahl GmbH \& Co KG [online]. 2021 [cit. 2021-06-13]. url: bttps://mmw.bobleredelstabl.com/app/uploads/sites/92/2019/09/M398En.pdf

[11] KRBAŤA, M., MAJERÍK, J., BARÉNYI, I., ECKERT, M., CEP, R., SEDLÁK, J., SAMARDŽIĆ, I. (2022). Dilatometric analysis of cooling curves for high strength steel x155crmov12 (2022) Metalurgija, 61 (1), pp. 193196.

[12] KRBAŤA, M., MAJERÍK, J., BARÉNYI, I., ECKERT, M., ČEP, R., SEDLÁK, J., SAMARDŽIĆ, I. (2022). Experimental determination of continuous cooling transformation diagram for high strength steel x155crmov12 (2022) Metalurgija, 61 (1), pp. 185-188.

[13] MORAVEC, J., NOVÁKOVÁ, I., VONDRÁČEK, J. (2020). Influence of Heating Rate on the Transformation Temperature Change in Selected Steel Types. Manufacturing Technology. 2020;20(2):217-222. doi: $10.21062 / \mathrm{mft} .2020 .024$.

[14] KUČEROVÁ, L., BYSTRIANSKÝ, M., JENÍČEK, Š. (2019). Thermo-mechanical Treatment of $0.4 \mathrm{C}-0.6 \mathrm{Mn}-2 \mathrm{Si}$ Steel with Various Soaking and Annealing Hold Temperatures. Manufacturing Technology. 2019;19(1):95100. doi: 10.21062/ujep/250.2019/a/12132489/MT/19/1/95.

[15] AMINI, K., SAFARI, M., SHAFYEI, A. (2016). Investigation of hardness and wear behaviour of the deep cryogenic treated 1.3255 tool steel, pp. 294-303, JOURNAL OF THE BALKAN TRIBOLOGICAL ASSOCIATION, Bulgaria , ISSN1310-4772. 